\title{
Misinformation as a Starting Point for Critical Thinking
}

\author{
David A Banks \\ University of South Australia, Adelaide, Australia
}

david.banks@unisa.edu.au

\section{Abstract}

The media generally, and the web in particular, offers learners access to increasingly large amounts of data. Some of this will be verifiable, some will be inaccurate or out of date and some will be either accidentally or deliberately untrue. Failure by students to recognise the existence of misinformation, deliberate or accidental, will lead to the uncritical use of web-sources materials with consequential impact on the value and quality of the work produced. This paper suggests that this potential problem can be turned into an educational benefit by highlighting the problem by stressing the need for students to enhance their critical thinking skills in ambiguous data and information environments.

Keywords : Misinformation, web, argument, inquiry, interpretation

\section{Introduction}

At the launch of HealthInsite, an initiative to provide reliable information on health matters, Dr Michael Wooldridge, Minister for Health and Aged Care in the Australian Government commented that "[The] vast amount of unfiltered information [on the Web] can be overwhelming and far from providing the information people are after, it can lead to confusion and even be dangerous in the misinformation it provides." The danger for learners who fail to recognise the existence of misinformation together with genuine information is that they may use this information uncritically in their study, leading to the presentation of unacceptable work. As educators we typically encourage our students to use the web as a tool to help them develop their understanding, but we must help students to recognise the dangers of blindly believing everything that lies on the web. We need to help them develop attitudes and thinking tools that will enable them to deal with the wealth of untested material that lies at their finger-tips. We need to first of all alert the $m$ to the existence of and reasons for misinformation, and secondly to lead them to develop a critical approach towards information in general. If we can also help them to take a critical view of all sources of information: text books, 'experts' (including academics), politicians and so on we should be able to take an even-handed and informed approach to academic study and provide them with a vital lifelong skill.

The deeper educational justification for leading students towards developing critical thinking and the ability to deal with ambiguity can be found in the writing of educators such as Dewey (1910), who states that if the first available suggestion is accepted then this would be uncritical thinking with the minimum of reflection. He considers reflection, or critical thinking, to be a process of seeking further evidence, gathering new data and testing the suggestion in order to either 'bear it out or else make obvious its ab-

Material published as part of these proceedings, either on-line or in print, is copyrighted by Informing Science. Permission to make digital or paper copy of part or all of these works for personal or classroom use is granted without fee provided that the copies are not made or distributed for profit or commercial advantage AND that copies 1) bear this notice in full and 2) give the full citation on the first page. It is permissible to abstract these works so long as credit is given. To copy in all other cases or to republish or to post on a server or to redistribute to lists requires specific permission from the publisher at Publisher@InformingScience.org surdity and irrelevance.' For Dewey reflective thinking implies 'judgement suspended during further inquiry' and to 'carry out systematic and protracted inquiry.'

Nuttgens (1988) offers the view that 'in any design task there is more than one answer to the problem; and there may indeed, be no completely satisfactory answer to it anyway. Furthermore, all 
design problems are continuous'. He states that 'the mark of an educated person is that issues are no longer simple, that they are not black or white, that the truth lies somewhere in the middle, and that there is no escape from knowing one's mind and making one's own decisions'. He felt that is was vital that this focus on autonomy and informed decision making was a key element of education and that 'any educational system that fails to make people responsible for themselves must be a failure'

Before considering how students can be helped to deal with the uncertainties, ambiguities, and multiple interpretations that arise from the existence of misinformation on the Web, some issues relating to misinformation will be explored.

\section{Data, Capta, Information and Misinformation}

The terms data and information are often used synonymously, but this is not strictly correct, as the relationship between them is that information is derived from data. (Anderson, 1989) Data would include '3', 'May', tables of measurement from an experiment or the number of vehicles owned by people under the age of 25. The data may have been recorded correctly or incorrectly, that is there may have been data capture errors, for example ' 3 ' may have been recorded for a true data of ' 5 '. Such errors may be a result of accidental misreading, deliberate distortion or incorrect interpretation of an instrument or situation.

For example a data value lying at a boundary point may be recorded as one value by one observer and as a different value by another observer. Data can be expected to have levels of accuracy and precision and to have been collected at a specific moment in time and recorded in a particular format. When we put data into context it becomes information and what we then infer from the data is a result of human processing, or interpretation.

Thus, different individuals in different settings or at different times may well arrive at different interpretations of the same raw data. Checkland and Holwell (1998), use the term 'capta', this being the result of selecting some data for special attention or for creating new categories of data that have some specific meaning for a specific purpose. They also use the term to refer to data where the observer reacts to some item of data and pays particular attention to it. Once data has been selected for attention, thereby becoming capta, it is contextualised, or enriched by relating it to a broader view and through a process of meaning attribution becomes information. This attribution process may of course be flawed, as may be the capture process - once again the recorded value of ' 3 ' may be seen as ' 5 '. (Interestingly in this case this means that the two flawed aspects of the incorrect data recording and later incorrect access cancel each other out and the data is restored to its original actual value).

Information, then, is the product of a process of selective observation, interpretation within a particular belief system or worldview, recording, reading and re-interpretation. The reading and re-interpretation may take place within a different belief system or worldview to that used at the capture stage. A defect at any stage of this process will lead to an incorrect outcome, that is, to a state of misinformation. This defective process may be the result of accidental or deliberate actions. Even apparently simple situations leave themselves open to the potential for a process that leaves some people believing one view to be true and other believing the opposite to be true even though both are exposed to the same underlying data.

\section{Misinformation as a Product of Multiple Interpretations}

An event that captured the attention of South Australians was the eclipse that was visible from parts of that State on December $4^{\text {th }}, 2002$ many people deciding that they wished to witness this rare event. The question that many wanted answers to related to the issue of how best to actually observe this event. Prior to the event newspapers, television and the web provided some information intended to help potential observers decide upon the safest way to view the spectacle. Some of that material is presented here to show how the outcome of this plethora of data and information could probably be classed more as 
misinforming than informing the public as a result of multiple interpretations offered by different parties.

One newspaper, The Australian, reported on November $27^{\text {th }} 2002$ that the South Australian Department of Human Services, the Royal Australian and New Zealand College of Opthalmologists [sic] and the Optometrists Association of Australia clearly warned that 'there is no consumer product capable of making it safe to watch the eclipse' and advised people to view the solar event via live webcast or television. (Note the incorrect spelling of ophthalmologist in the newspaper report). In response, astronomers (unnamed) 'condemned' this advice, noting that scientists (un-named) have been witnessing eclipses for the past 15 years using NASA-sanctioned "eclipse shades". (No mention is made of how eclipses were viewed before the advent of 'NASA-sanctioned eclipse shades'). One eclipse follower, a member of the Astronomical Society of South Australia, added weight to this view by offering the comment that "This is my $14^{\text {th }}$ solar eclipse and I can still see'. (No evidence was presented about frequent observers who may have developed eye problems) It was also noted that the 'French Ministry of Health bought 100,000 shades for the 1999 eclipse when over 15 million pairs were distributed without incident'. (The figures here seem to be a little confusing). A source on the web suggested that the French health ministry had agreed with opticians to provide 60 million pairs of 'high strength sunglasses' priced at 50 pence each (Guardian Newspapers, April, 1999). A different web source later reported that the French government 'ordered the recall of a million pairs of the sunglasses ... Although the glasses have been stamped with the "CE" label, supposedly proving that they meet safety standards, doctors say that the protection they offer is so poor that users who wore them to view the eclipse would "risk irreversible lesions on the retina leading to blindness"'. (Sunday Times, August,1999) The eclipse shades of concern in Australia were described as '\$7 cardboard sunglasses', (descriptive, but possibly pejorative language?) but there were also references to eclipse shades tested and certified by the British Standard Institute, the International Astronomical Union and by German certification. There do not appear to be any reported standards for such glasses in Australia.

The Advertiser newspaper led its front page on Saturday November $30^{\text {th }}$ with the bold headline "DON'T LOOK - eclipse glasses can hurt your eyes" and reported that the Western Australian Government was ready to 'hit vendors with $\$ 100,000$ fines'. No scientific counter-arguments were offered in the article and the only other data provided was that in the 1999 eclipse in the United Kingdom '20 people went to hospital for eye injuries. Four of those had used eclipse glasses, which had dislodged in use.' (No me ntion was made of the causes the problem for the other sixteen. Presumably had the damage been caused by cheap eclipse shades this would have been remarked upon).

The situation in the UK had been equally ambiguous for the 1999 eclipse. Advice from the UK Government's chief medical officer warned that sub-standard solar viewer glasses could lead to problems. The mixed messages led to the withdrawal of some eyeshades from sale at petrol station outlets but not at some large stores. One store commented that it was 'monitoring the situation, but as demand is still strong, viewers are still on sale'. (BBC News, 2003)

The above reports present a variety of data and views, many contradictory, about an event that could potentially cause serious eye damage to inappropriately prepared observers. Advice is presented from go vernment agencies, who presumably have access to expert advice, and contradictory advice from astronomers and from distributors of a product that may, or may not, be NASA-sanctioned and may, or may not, meet the standards laid down by other countries. The direct evidence for actual eye damage, or lack of it, comes from a small sample of people who have survived previous similar events apparently without damage and from statements that 'dislodged' eclipse shades do lead to eye damage. On the basis of the material presented here what reasonable position could be put forward to an individual who wanted to know if they, or their children, should view the eclipse with $\$ 7$ eye shades? 


\section{Start with Intuition?}

The sources outlined above contain a mixture of data, belief, information, possible mis-information, errors, and conflicting 'expert' advice. The problem for the potential eclipse viewer is that of deciding which evidence may be reliable or perhaps even 'true'. In the circumstances described many people would intuitively be nervous about looking directly at the sun. This suggests that reliance on intuition could be a useful starting point for sifting real information from misinformation. If we are presented with evidence that supports our previous understanding of an issue we might see the new evidence is confirmatory and therefore believable. If we feel that staring at the sun would damage our eyes then we are not likely to be convinced, even by 'experts', that it is safe to carry out this activity. In these circumstances we may feel that ' $\$ 7$ eclipse shades made of cardboard' will provide little protection. The fact that the selling of these objects may lead to the seller to receive a $\$ 100,000$ fine from the government could add to our conviction that these are unsafe devices. On the other hand, if we believe that the shades meet the standards laid down by other countries, are based on NASA technology and the testimony of actual observers rather than Government bodies we may take a different view. We would need to ask if we really have been 'informed' by the materials presented to us. If the eyes of people using eclipse shades are damaged then they have been misinformed by one group of commentators. If the eyes of people using the shades are not damaged then they have been misinformed by the other group of commentators. If people avoided watching the eclipse in the belief that it was too dangerous but subsequent reports indicated that there had been no problems they would probably have felt aggrieved and possibly be willing to view future events with cheap eyeshades.

This simple case illustrates the difficulties of dealing with multiple interpretations of apparently the same set of underlying data. In fact, despite the volume of material, the data made available is not sufficient to allow anyone to make an informed choice. Our individual views of the level of risk would be the main guide in making the choice here and this is a potential key to assessing the possibility of material being misinformation, which is how well it fits with our existing knowledge of the issue in question. However, two objections can be raised to this approach. Firstly, if our knowledge is sparse we may not be able to judge how much dissonance there is between possible interpretations. A student told by a lecturer that business process re-engineering (BPR) or 'best practice' are the keys to success for business may find it difficult to deal with another lecturer who proposes the opposite view, particularly if they have no practical experience of either BPR or best practice. Secondly, too much conviction towards one particular view may lead us to reject a conflicting view without deep consideration of the alternative. For example there is a web page in which Charles K. Johnson, president of the International Flat Earth Research Society, states that "The facts are simple - the earth is flat."(Schadewald R J, 1980) He continues; "Nobody knows anything about the true shape of the world. The known, inhabited world is flat. Just as a guess, I'd say that the dome of heaven is about 4,000 miles away, and the stars are about as far as San Francisco is from Boston...the world is as flat as a phonograph record with the North pole at the center and an ice wall, 150 feet high is at the outer edge'. Ridiculous? To be dismissed as outright nonsense? Few of us have had the opportunity to see the earth from space so how can we say it is not flat? Instead of direct experience we have to rely on the word of others and assume that they tell the truth because it appears to be accepted in all of the circles we know of. The defect here is that we are relying on our informers not to have misinterpreted their observation, nor to have misinformed us for some specific purpose of their own.

When Copernicus made the case in 1543 that the earth revolved around the sun, rather than the sun round the earth, this claim was also dismissed as total nonsense as it flew in the face of accepted views of the time. If we are bound by conventional wisdom we may thus dismiss the concept of engines that run on water, machines that generate more output than input, that the moon landings were filmed in a studio and so on. We cannot know for sure if any of these claims are true (and there are many such claims on the Web) unless we see them for ourselves - and even then it would depend upon our ability 
to test the situation in a rigorous way. Given this difficulty we need to identify thinking tools that can help us weight the available evidence in a structured manner so that we can work through all of the available data, information and misinformation and arrive at a reasonable conclusion.

A reasonable approach, therefore, is try to gather as much pertinent and evidence as possible and arrive at a well-argued conclusion that expresses our best understanding, at that time, and on the basis of referenced evidence. We can use such words as 'maybe', 'possibly', definitely' to qualify our statements depending on our strength of feeling about the evidence we have examined, interpreted and presented to others. We can attempt to look for rebuttals to aspects of our understanding and find ways to counter these. We may have to accept that having worked through this process our initial position was based on prejudice, ignorance or made use of incorrect data or that we have acted in a misinformed way. To achieve this requires the gathering of as much evidence as possible, weighing of that evidence and the development of an argument within a structured framework. The alternative to this is to accept the first piece of evidence presented and ignore any subsequent contradictions, or to follow our own beliefs and possibly dogmatic views. Such 'uncritical acceptance', characterised by avoidance of complexity, uncertainty, change and potential contradiction of possibly long held views would, however, offer minimal opportunity for learning (Locke, 1690). As educators we have a responsibility to help our learners avoid such uncritical approaches and instead help them to confront issues and develop an even-handed approach, even though this may be challenging for some students.

\section{Developing Approaches to Deal with Misinformation}

The first step in helping students deal with misinformation is to alert them to the possible multiple interpretations that can exist on the Web. One useful way that the author has used is to introduce students to the web pages dealing with the High Frequency Active Auroral Research Program (HAARP). There are a wide range of web sites that relate to this project, including the official HAARP site that provides details of the project and its purposes (HAARP home page). Accessing just this site would suggest that it is an interesting American scientific program involved with ionospheric research, with web-cam images of the antenna systems available. However, further searches will reveal pages relating to weather control, mind control, damage to the upper atmosphere, the Strategic Defence Initiative, early work by Tesla in beam energy and links to crashed flying saucers. The spectrum of interpretation therefore goes from beneficial and benign research through to 'messing with mother earth' (Manning J and Begich N, 2002). Much of the linking material, for example key players in the project, links to previous beam weapon work, Tesla, patents etc, appears to be genuine but at some point on the spectrum students will decide that it has reached the 'science fiction' level and the ideas are not credible. This point will vary from student to student. Interestingly this material is also useful for introducing students to semiotics as the official site has a fluttering American flag and the 'science fiction' end has the dark eyed, large headed alien. Once students recognize the difficulties of dealing with this range of information, and in the way it is presented, in a reasonably 'fun' way they are more motivated to search for contradictions to other materials that they locate on the web.

Once students have been alerted to the prevalence of potential misinformation, they need to be provided with some tools to help them deal with critical evaluation in an organized way.

\section{Dealing with Misinformation}

A useful first step in dealing with potential or actual misinformation is to gather as much data as possible and to critically examine that data. For example, attempting to find out the number of people using the Web will lead to a range of possible numbers, many of which have been derived in different ways. The HealthInsite launch mentioned in the opening of this paper suggests that 'In the 12 months to February this year, for instance, some five million Australian adults - that's almost of all Australian adults went searching on the web - a leap of some two million people on the previous year.' The questions we 
might find it useful to ask would be 'Does this really mean that nearly all Australian adults have been on the web?', 'How do they know - and how do they know it is adults rather than schoolchildren?' and so on. Checking these statistics against other sources would help us develop a view of the credibility of the rest of the information offered in this press release. A useful set of questions that can form the basis for a questioning approach are offered by Locke (1690):

(1) What is the number of items presented (both for and against the issue at hand ... )

(2) What is the integrity of the source. (genuine web site or 'spoof' site ...)

(3) What is the skill of the witness (first hand report, second hand, qualifications, access to sources ...)

(4) What was the purpose of the author (informing, self-promotion, advertising, political agenda ...)

(5) What is the consistency of the parts, and the circumstances of the relation. (Seeking the 'big picture', connections ... )

(6) What contrary testimonies can be found (steps 1 to 5 followed for alternative arguments)

We would need to add to this list a question relating to the age of the materials under review to provide a temporal frame.

These questions provide a useful starting point for more detailed thinking but another vital que stion to ask would be 'What is my own view of the issue under investigation?' Understanding of the personal 'lens' being used to view the materials would reveal any potential personal biases in interpretation of material or in likely weights applied to the various views identified.

This process of debate, questioning, challenging and active use of the materials is vital to ensure that any individual distortions of epistemic assumptions, belief systems, social norms, cultural or language codes are revealed to us. (Schön, 1983) This testing of the validity of potentially contested meaning of an interpretation through consensual process requires that the conditions for discourse need to meet a number of criteria (Mezirow, 1991):

- $\quad$ Participants have accurate and complete information

- $\quad$ Be free from coercion and distorting self-deception

- $\quad$ Be able to weigh evidence and assess arguments objectively

- $\quad$ Be open to alternative perspectives

- $\quad$ Be able to become critically reflective upon presuppositions and their consequences

- Have equal opportunity to participate (including the chance to challenge, question, refute and reflect and to hear others do the same) and

- $\quad$ Be able to accept an informed, objective, and rational consensus as a legitimate test of validity

A carefully managed debate can achieve these criteria in an educational setting. If this is supported by the type of argumentation structures developed by Toulmin, (Toulmin, 1999) students can be helped to develop well-argued differentiation between information and misinformation. Such approaches can be incorporated into the learning environment in a pragmatic way through a variety of teaching and learning approaches.

\section{Conclusion: Process or Product?}

This paper has examined some issues relating to misinformation in web and other communication media. It has suggested that recognition that misinformation exists in these media can be used as a trigger 
for developing critical approaches to thinking about a wide range of propositions. It is, of course, impossible to say that the outcome of critical thinking will actually differentiate between true and false information given the nature of the interpretive processes involved and often no access to some source data. It will, however, lead to a position where an individual can work through a rigorous process and arrive at a qualified position in regard to the issue under scrutiny. Nuttgens (1988) comments that education 'must follow a process, rationally and critically, which must be completed in order to make sense at all and cannot be left off after study of the difficulties (in the respectable academic way of; on the one hand $\ldots$ and on the other ...). Furthermore, its end is a product or activity, not a question, a challenge or a theory. Above all it demands cooperation, the ability to work with other people. Nothing can either be found out in the way of needs or realised and implemented without working as a group or a team.'

The approach advocated here moves strongly away from 'giver of knowledge' (or 'sage on the stage') and strongly towards 'guide on the side', perhaps even leaning into 'explorer mode'. This latter mode is very much more a co-learning approach where all parties, including staff, are engaged in the learning process and are exposed to new ideas and where false trails are seen as useful excursions rather than failures to achieve an intended goal. This is the preferred learning facilitation mode of the author but it is acknowledged that such an approach carries considerable risk. This risk applies both to staff and to student. For students not used to such an approach there is considerable discomfort as they try to find clear, unambiguous and unchanging goals, these often being framed in the context of employable skills. For staff the polarised feedback that may become evident in course/staff evaluation questionnaires when inquiry based learning is used could easily be viewed as implying poor or uncaring teaching. The approach could also be viewed as being too much from the 'liberal' tradition of adult education, reflecting out of date values for the modern consumer oriented educational systems, as it emphasises process rather than just product. The dangers of such exploratory teaching and learning approaches are even more sharply raised in a potentially litigious world where course outlines become legal documents with the onus on staff to prove that they have delivered what the 'customer' expected and exactly in the manner in which it was expected. Perhaps all teaching materials should contain disclaimers similar to those found on some web pages, indicating that what is expressed is purely the interpretation of that member of staff and incorrect or misleading material may have been presented?

Misinformation, ambiguity and uncertainty are not just features of the web, they are also features of our everyday lives. The web offers increasingly rapid access to a growing amount of views, many contradictory, some incorrect and some deliberately misleading. The critical exploration of this plethora of often transient material through critical and informed debate as part of lifelong learning is surely a key skill for future citizens to enable them to develop or enhance their ability to act in informed ways. It is a responsibility of educators to recognise their role in society and help develop critical thinking skills to enable individuals to challenge and test any views that are presented to them, no matter who it is that presents those views, be they educators, politicians, scientists or any other member of society. Viewing the information world as one also containing potential misinformation does require that learners are willing to critically test, and possibly abandon, previously held ideas. This suggests a non-linear learning approach characterized by initial learning, critical testing, re-learning, and potential abandonment of views or directions of thinking in favour of alternatives. This may initially be difficult for those students used to more linear approach, with a single objective 'truth' as a target, but if placed within an appropriate frame and supported by pragmatic thinking tools they should begin to see the search for meaning as an active, challenging and learner-centric activity. John Locke (Locke, 1690) born in 1632, captured the spirit of such inquiry when he wrote:

Thus he who has raised himself above the alms-basket, and, not content to live lazily on scraps of begged opinions, sets his own thoughts on work, to find and follow truth, will (whatever he lights on) not miss the hunter's satisfaction; every moment of his pursuit will reward his pains with some delight; and 
he will have reason to think his time not ill spent, even when he cannot much boast of any great acquisition.

\section{References}

Anderson, R G. (1989). Information Systems in Development and Operation. Pitman, UK.

BBC News. (2003). http://news.bbc.co.uk/1/sci/tech/specials/total eclipse/414109.stm

Checkland, P. and Holwell, S. (1998). Information, Systems and Information Systems: Making Sense of the Field. Wiley, Chichester, UK.

Guardian Newspapers. (1999, Saturday April 10). http://guardian.co.uk/Print/0,3858,3852450,00.html

HAARP home page. http://www.haarp.alaska.edu

HealthInsite launch press release. (2002 November 14). http://partners.health.gov.au/mediarel/yrl 999/mw/mwsp990809.htm Locke, J. (1690). An Essay Concerning Human Understanding. Abridged by John W Yolton, 1977, J M Dent and Sons, UK. Manning, J. and Begich, N. (n.d.). Angels don't play with this HAARP. http://www.2012.com.au/HAARPP.html

Mezirow, J. (1991). Transformative Dimensions of Adult Learning. Josey-Bass, USA.

Nuttgens, P. (1988). What Should We Teach and How Should We Teach It? Biddles, UK.

Schadewald, R. (1980). http://www.lhup.edu/ dsimanek/fe-scidi.htm

Schön, D A. (1983). The Reflective Practitioner. Basic Books, USA

Sunday Times website, 3 August 1999, http://www.hermit.org/Eclipse/1998-08-11/ST-French.html

Toulmin, S. (1999). The Uses of Argument. Cambridge University Press, Cambridge, UK.

\section{Biography}

David A Banks is a lecturer in the School of Accounting and Information Systems at the University of South Australia. He currently manages two courses, 'Collaboration and E Commerce' and 'Information Systems Development Methodologies'. Prior to joining the University of South Australia he worked at a UK university for twelve years after having spent sixteen years working with voice, data and video systems for a large UK telecommunications organisation. His research interests are in the areas of IS education, group process support systems and project management. 